\title{
Guía de merendar saludablemente para el adulto mayor frágil'
}

\author{
Paula G. Harris-Swiatko y Wendy J. Dahl
}

El adulto mayor frágil es un grupo especial que consiste en adultos mayores que sufren de discapacidades o enfermedades que pueden afectar su capacidad para funcionar en la vida cotidiana. Muchos tienen la dificultad de realizar y completar tareas sencillas de manera que requieren la asistencia de un cuidador. Entre otros retos que pueden enfrentar a diario y puede ser difícil para este grupo, son la preparación de los alimentos y el consumo de una dieta saludable. Si los adultos mayores frágiles tienen problemas para preparar y consumir una dieta saludable y satisfacer sus necesidades nutricionales, la malnutrición se puede convertir en una preocupación.

El adulto mayor frágil enfrenta retos únicos que pueden interferir con el cumplimiento de sus necesidades nutricionales. Por ejemplo, los adultos mayores frágiles pueden tener problemas para masticar y tragar (deglutir). También, pueden tener problemas gastrointestinales como acidez en el estómago, la pérdida de apetito y pueden sufrir molestias al comer ciertos alimentos. La debilidad de los huesos y la pérdida de la masa muscular también pueden perjudicar la habilidad de completar tareas físicas, como la de cocinar. Retos como estos pueden dar lugar al desánimo, a la disminución del consumo de alimentos y a patrones alimenticios irregulares, que además pueden conducir a diversas deficiencias nutricionales. Con el fin de ayudar a este grupo de personas a superar alguno de estos retos de preparar y comer una dieta nutritiva, los cuidadores necesitan tener acceso a ideas y herramientas que les ayuden a proporcionar a los adultos mayores frágiles una buena nutrición. Meriendas sencillas y nutritivas que sean fáciles de hacer son una buena manera de añadir alimentos nutritivos a sus dietas.

\section{Condiciones y enfermedades comunes en adultos mayores frágiles}

Los adultos mayores frágiles se enfrentan a retos especiales debido a sus condiciones relacionadas a la edad y a enfermedades que pueden disminuir su calidad de vida y hacer difícil la preparación y el consumo de una dieta saludable. Muy a menudo, el adulto mayor frágil que es capaz de vivir en su hogar, necesita la asistencia de un cuidador que les ayude con las tareas cotidianas, como preparar las comidas. Las enfermedades relacionadas a la edad que pueden causar los retos en tareas cotidianas son las siguientes:

- El síndrome de fragilidad se desarrolla debido a la pérdida de la masa ósea y de la masa muscular durante el envejecimiento. El síndrome de fragilidad afecta la capacidad de completar las tareas diarias como la de cocinar.

- La debilidad muscular es comúnmente desarrollada por el envejecimiento. La debilidad muscular a menudo conduce a la disminución en actividad y la fragilidad ya

1. The English version of this document is FSHN12-19, A Guide to Healthy Snacking for the Frail Older Adult. Este documento, FSHN12-19s, es uno de una serie de publicaciones del Food Science and Human Nutrition, Servicio de Extensión Cooperativa de la Florida, Instituto de Alimentos y Ciencias Agrícolas, Universidad de la Florida. (UF/IFAS). Fecha de primera publicación: abril 2013. Visite nuestro sitio web EDIS en <http://edis.ifas.ufl.edu>.

2. Paula G. Harris-Swiatko, MS, and Wendy J. Dahl, assistant professor, Food Science and Human Nutrition Department, University of Florida Institute of Food and Agricultural Sciences, Gainesville, FL 32611. 
que no se tiene la fuerza para hacer las cosas a las que se estaba acostumbrado a hacer.

- La osteoporosis es una enfermedad relacionada con los huesos donde estos se vuelven débiles y/o frágiles. Los huesos débiles conducen a un mayor riesgo de caídas y fracturas. Muchas veces los huesos rotos son el resultado de estadías largas en el hospital. Esto es un riesgo para la salud del paciente debido a que una estadía prolongada en el hospital puede debilitar el sistema inmunológico y disminuir las probabilidades de recuperación

\section{La nutrición para los adultos mayores frágiles}

A medida que la gente envejece, las necesidades nutricionales cambian. Ciertas vitaminas y nutrientes comienzan a tener más importancia, tal como el calcio y la vitamina D para la salud ósea, la proteína para la curación y para la salud muscular. La malnutrición es más probable que ocurra en las personas encerradas o que mantienen en el hogar, más en adultos mayores frágiles que en adultos mayores sanos porque aquellos adultos mayores encerrados en el hogar a menudo tienen más dificultad al acceso de los alimentos saludables o a los supermercados. Comúnmente ellos se encuentran en el hogar debido a que poseen alguna discapacidad o enfermedad y estas condiciones hacen que el prepararse los alimentos sea un reto. Para lograr una salud óptima, es importante consumir una variedad de alimentos de todos los grupos de alimentos, lo cual ayuda a garantizar que se obtengan todos los nutrientes necesarios. El consumir meriendas que proporcionen los nutrientes claves y que sepan bien, es una manera sencilla e importante de ofrecer a los adultos mayores frágiles los nutrientes que son críticos para su salud.

\section{Las necesidades de proteínas}

La proteína es importante para las personas que están envejeciendo, pero es especialmente importante para los adultos mayores frágiles. La proteína tiene muchas funciones. Esta repara las células, las mantiene, reemplaza los tejidos y produce la hemoglobina (los glóbulos rojos que transportan el oxígeno). Es esencial para la coagulación de la sangre. También produce los anticuerpos para luchar contra las enfermedades. Las buenas fuentes de proteínas son las carnes, aves, pescados, productos lácteos y legumbres.

\section{El calcio y la vitamina D}

A pesar de que todas las vitaminas y minerales son necesarias para una salud óptima, el calcio y la vitamina D son muy importantes para el adulto mayor frágil. Un nivel adecuado de calcio y vitamina $\mathrm{D}$ es necesario para mantener los huesos. Más vitamina $\mathrm{D}$ es necesaria en la dieta para la síntesis de la piel la cual disminuye con la edad. Existen maneras de cómo añadir más calcio y vitamina $\mathrm{D}$ en la dieta. Los productos lácteos, particularmente la leche, yogur y queso, son altos en calcio. Otras fuentes buenas incluyen las versiones fortificadas en calcio del jugo de naranja y bebidas a base de soya. Las buenas fuentes de vitamina $\mathrm{D}$ incluyen la leche, algunos yogures, pescado, hígado y yema de huevo, así como los panes fortificados y el cereal. Sin embargo, muchos panes y cereales no tienen la vitamina $\mathrm{D}$ añadida por lo que es importante revisar a lista de ingredientes.

\section{Ideas para las meriendas}

El tomar decisiones inteligentes para la selección de las meriendas ayuda a asegurar que los adultos mayores frágiles satisfagan sus necesidades nutricionales. Estas son algunas meriendas sencillas y nutritivas que son apropiadas para los adultos mayores frágiles. Estas son fáciles de masticar y de tragar, como también fáciles de preparar iy tienen un buen sabor! Cuando planifique las meriendas para el adulto mayor frágil, es importante incorporar una variedad de opciones de alimentos saludables. Esto asegura que las meriendas están proporcionando un balance de nutrientes.

- Los huevos endiablados: Los huevos endiablados son una fuente buena de proteína. Comience por hervir los huevos hasta que se endurezcan (diez minutos). Escurra los huevos y luego enfríelos con agua fría o por refrigeración. Coloque los huevos en una tabla limpia para cortar. Remueva las cáscaras de los huevos y corte longitudinalmente por la mitad. Retire la yema de huevo con una cuchara y colóquelas en un plato. Añada mayonesa a las yemas y bátalas hasta que estén húmedas y cremosas. Vierta la mezcla de la yema de huevo en los blancos del huevo y espolvoree con paprika. Sirva frío.

- El requesón con frutas enlatadas: El requesón es una merienda que es bien suave y fácil de comer. También ofrece una fuente buena de proteína. Las peras enlatadas o los melocotones enlatados con poco jarabe son sabrosos y le dan al requesón más sabor. Abra la lata de fruta y escurra. A continuación, corte la fruta en pequeños cubos y combínelos con una cuantas cucharadas de requesón . Mezcle bien y sirva frío.

- La leche con sabor: Las leches con sabor, como las de sabor a chocolate o a fresa, proporcionan las proteínas, 
calcio, vitamina $\mathrm{D}$, energía y además son una merienda rápida, fácil de tomar y sabrosa. Las versiones estables en estantería o no perecederas y que vienen de forma individual son particularmente convenientes.

- El yogur con frutas: Los yogures son una buena opción para la merienda para el adulto mayor proporcionando una buena fuente de proteína y calcio. Sirva media taza de yogur natural o con sabor cubierto con bayas tales como fresas o frambuesas frescas.

- El pudín de leche: El pudín es una merienda sabrosa y fácil de tener a mano. El pudín puede ser comprado en opciones como artículo no perecedero, en porciones individuales o fresco, el cual requiere refrigeración. Además de los sabores comúnmente disponibles, como el de vainilla, de chocolate y el de caramelo, que son sabores tradicionales para los adultos mayores, también están disponible con sabores de arroz y tapioca.

- Los batidos: Los batidos son fáciles de preparar y poseen una gran cantidad de sabores e ingredientes para elegir. Un batido básico se comienza vertiendo una taza de leche en la licuadora. Agregue $1 / 2$ taza de yogur o helado y fruta fresca. Usted le puede agregar cualquier fruta pero intente escoger frutas que combinen bien, como el banano con las bayas. Rocíe miel en la parte superior para añadirle un poco de dulce. Mezcle en alta velocidad hasta que quede suave. Vierta y sirva.

- El queso: El queso es delicioso y fácil de preparar. El bloque de queso tipo cheddar, suizo y queso mozzarella son buenas opciones, pero también intente otras variedades y especialidades de queso. Corte el queso en pequeños cubos o compre paquetes de queso que vengan ya en cubitos.

- Helado con llovizna de fresa: El helado es una golosina deliciosa que la mayoría de las personas simplemente no pueden resistir. El helado viene en una variedad de sabores y también en diferentes contenidos de grasa. Los helados de primera calidad son generalmente altos en grasas pero también con mucho más sabor. Intente servir el puré de fresas como llovizna encima del helado.

- Ensalada de atún: El atún puede ser de bajo costo y fácil de preparar. Si el sodio es un problema, el atún puede ser enjuagado. Para una ensalada de atún rápida, solo abra la lata, escurra, enjuague, mezcle con mayonesa y con condimentos.
Para los adultos mayores frágiles es importante una dieta saludable que tenga un buen sabor. Las dolencias pueden hacer difícil el preparar las comidas saludables y las meriendas se hacen más importantes para asegurar un consumo óptimo de nutrientes. A menudo, es necesario un cuidador para asistir con las tareas diarias como son la compra y la preparación de alimentos. Sirva meriendas deliciosas que sean fáciles de preparar, asequibles y que satisfagan las necesidades nutricionales de los adultos mayores frágiles. El momento de la merienda debe ser agradable para ambos, el adulto mayor frágil y el cuidador.

\section{Referencias}

Bandinelli, S., and B. Lunenfeld. 2010. "Frailty and the Role of Nutrition in Older People: A Review of the Current Literature." Acta Biomed 81(Suppl. 1): 37-45.

Heuberger, R. A. 2011. "The Frailty Syndrome: A Comprehensive Review.” J. Nutr. Gerontol. Geriatr. 30(4): 315-68. 